\title{
PRIVATIZAÇÃO E MERCANTILIZAÇÃO DA SAÚDE E CRISE NO RIO DE JANEIRO: O DESMONTE REALIZADO PELAS ORGANIZAÇÕES SOCIAIS*
}

\author{
Maria Inês Souza Bravo \\ Joseane Barbosa de Lima \\ Maria Valéria Costa Correia
}

\section{Apresentação}

A década de 1990 foi marcada pela ascensão do neoliberalismo que teve sua consolidação na criação do Ministério da Administração e Reforma do Estado (MARE) capitaneado por Bresser Pereira, durante o governo de Fernando Henrique Cardoso. Com a justificativa de enfrentar a crise fiscal do Estado, propiciou a sua minimização para dar respostas às demandas da classe trabalhadora e a sua maximização para atender às demandas do capital. Nessa direção, o fundo público tem sido repassado, cada vez mais, para o setor privado executar políticas sociais, antes de responsabilidade do Estado, mediante contratos de gestão. Para tal finalidade, surgem os denominados novos modelos de gestão, entre os quais as Organizações Sociais, ou seja, entidades privadas, que passam gerir as políticas sociais.

No cenário mundial, desde as décadas de 1980 e 1990, as recomendações do Banco Mundial e das demais instituições financeiras internacionais estavam centradas nos programas de estabilização econômica e de ajuste estrutural para enfrentar a crise da dívida dos Estados, que implicavam na sua reforma. Esse Banco, por meio de documentos, fez reiteradas recomendações para o repasse da gestão pública ao setor privado, com o intuito de que o Estado passasse de executor de serviços de saúde, a regulador, mediante transferência de recursos públicos para esse setor. O eixo de suas propostas tem sido a ampliação do setor privado na oferta de bens e serviços de saúde, incentivando o Estado a repassar recursos para "qualquer entidade" prestar os serviços de saúde (Banco Mundial, 1991, p.117).

O documento de 1995: "A Organização, Prestação e Financiamento da Saúde no Brasil: uma agenda para os anos 90", deixa claro o novo papel regula-

*DOI - 10.29388/978-65-86678-20-8-0-f.125-146 
dor atribuído ao Estado que deverá concentrar esforços apenas "no financiamento e no controle desses serviços ao invés do seu oferecimento direto" (Banco Mundial, 1995). O documento de $2007^{1}$ enfatiza a necessidade de desenvolver e implementar maior autonomia e accountability às unidades de saúde e aponta para vários modelos de gestão autônoma [...] tais como o modelo das Organizações Sociais, entre outros" (Banco Mundial, 2007, p.79). As Organizações Sociais também são apontadas no documento de $2013^{2}$ como forma de dar mais autonomia às unidades de saúde, podendo o estado federativo escolher o modelo mais apropriado (Banco Mundial, 2013). Já no contexto de governo ultraneoliberal no Brasil, o documento do Banco Mundial de 2019: "Propostas de Reformas do Sistema Único de Saúde Brasileiro", aponta as Organizações Sociais em Saúde como o melhor caminho para a autonomia de gestão, a partir da crítica da rigidez das regras da administração pública.

A gestão dos estabelecimentos públicos de saúde por Organizações Sociais tem crescido no país ${ }^{3}$. Este artigo trata das Organizações Sociais como modelo de gestão que privatiza e mercantiliza o SUS, no contexto de contrarreformas ${ }^{4}$ neoliberais do Estado brasileiro, e analisa a particularidade desse processo no município e no estado do Rio de Janeiro e o seu impacto no desmonte do SUS, agravado pelo seu desfinanciamento e pela crise financeira desse estado. Está organizado em duas partes, a primeira aborda as origens das Organizações Sociais no Brasil e o seu alinhamento com as demandas do Estado maximizado para atender aos interesses do capital, por meio da captura do fundo público pelo setor privado, privatizando e mercantilizando a saúde pública. A segunda parte apresenta como tem ocorrido esse processo no município e no estado do Rio de Janeiro, a partir da análise de dados de realidade fruto de pes-

\footnotetext{
${ }^{1}$ Documento intitulado: “Governança do Sistema Único de Saúde (SUS) brasileiro: Fortalecendo a Qualidade do Investimento Público e da Gestão de Recursos".

${ }^{2}$ Documento: "20 anos de construção do sistema de saúde no Brasil: uma avaliação do SUS".

${ }^{3}$ Segundo dados da Pesquisa de Informações Básicas Municipais divulgada, em 2019, pelo Instituto Brasileiro de Geografia e Estatística (IBGE), o número de estabelecimentos de saúde municipais administrados por essas Organizações cresceu de 997 em 2014 para 1.756 em 2018, havendo um aumento de 76\% no período. No Estado do Rio de Janeiro são 302 estabelecimentos, referentes a 15 municípios, conforme os dados divulgados pelo IBGE. Disponível em: < https://valor.globo.com/brasil/noticia/2019/09/25/ibgenumero-de-organizacoes-sociais-que-geremestabelecimentos-de-saude-sobe-

76percent.ghtml>. Acesso em: 24 maio 2020.

${ }^{4}$ Expressão utilizada por alguns autores para designar o conjunto reformas realizadas pelo Estado brasileiro, a partir da década de 1990, regressivas do ponto de vista dos interesses da classe trabalhadora.
} 
quisas coordenadas por Bravo et al, entre 2012 e 2015, e Lima, em 2017, abordando sua influência no desmonte do SUS, no contexto de crise financeira do estado do Rio de Janeiro.

\section{As Organizações Sociais no Brasil e a privatização da saúde pública, no contexto de contrarreformas neoliberais}

As Organizações Sociais (OSs) surgem no contexto das contrarreformas do Estado brasileiro, durante o governo de Fernando Henrique Cardoso, dentro das propostas do Ministério Administrativo da Reforma do Estado (MARE) criado para implementá-las. São apresentadas como um dos novos modelos de gestão das políticas sociais para modernizar e desburocratizar o Estado. No entanto, compõem um conjunto de ações do Estado para enfrentar a crise do capital, favorecendo os interesses do grande empresariado, especialmente na área da saúde.

\section{1 - A origem das Organizações Sociais no Brasil e a contrarreforma neoliberal}

No contexto de redefinição das funções precípuas do Estado, o Plano Diretor da Reforma do Aparelho do Estado (PDRE), de 1997, enumera propostas que estabelecem as bases de organização do Estado brasileiro que deveriam facilitar o ajuste fiscal, em especial, nos Estados e municípios e tornar moderna e eficiente a administração pública. A proposta então apresentada parte da existência de quatro setores dentro do Estado: (1) o Núcleo Estratégico do Estado; (2) as Atividades Exclusivas do Estado; (3) os Serviços Não exclusivos ou Competitivos, e; (4) a Produção de Bens e Serviços para o Mercado.

As formas de propriedade é que distingue os referidos setores. Assim, considera-se a propriedade estatal, a propriedade privada e uma terceira forma intermediária de propriedade, a chamada propriedade pública não estatal, representada pelas organizações sem fins lucrativos que não são propriedade de nenhum indivíduo ou grupo e estão voltadas diretamente para o interesse público. Segundo o PDRE (1997), cada setor do Estado pedirá um tipo de propriedade mais adequada, assim, no setor de atividades exclusivas de Estado, onde o poder típico de Estado é exercido, a propriedade também só pode ser estatal. Já 
para o setor não exclusivo ou competitivo do Estado, a propriedade considerada ideal é a pública não estatal, visto que se compreende que aqui não se exerce o poder de Estado, contudo, não pode ser considerada propriedade privada, já que se trata de um serviço de caráter público (Andreazzi e Bravo, 2014, p. 503).

Desse modo, todo o empenho é no sentido de publicizar os serviços considerados pelo PDRE como não exclusivos do Estado, sob o argumento de aumento da eficiência e qualidade dos serviços com redução de custos. Os serviços considerados não exclusivos são aqueles onde o Estado atua simultaneamente com outras organizações privadas, tais como educação, saúde, cultura e proteção ambiental, entre outros. A estratégia é transferir os referidos serviços para o chamado setor público não estatal, que uma vez fomentados pelo Estado, assumirão a forma de Organizações Sociais.

O Projeto de Organizações Sociais, no âmbito do Programa Nacional de Publicização, configura o modelo de organização pública não estatal voltada à absorção das atividades consideradas não exclusivas do Estado, por meio de contrato de gestão, mediante qualificação específica. Trata-se de uma forma de propriedade composta por associações civis sem fins lucrativos, aptas a serem parceiras do Estado na gestão pública, e cujas atividades estão voltadas para o atendimento do interesse público.

A lei n. 9.637/1998, aprovada pelo Congresso Nacional em maio de 1998, consolidou o Programa Nacional de Publicização proposto nos documentos elaborados pelo PDRE e estabeleceu critérios para qualificar como OS pessoas jurídicas de direito privado, sem fins lucrativos, cujas atividades seriam dirigidas ao ensino, à pesquisa científica, ao desenvolvimento tecnológico, à proteção e preservação do meio ambiente, à cultura e à saúde. Segundo Resende (2008), no âmbito do direito propriamente dito, a instituição das OSs não se trata de nova categoria de pessoa jurídica, mas de uma qualificação especial, isto é, um título jurídico concedido por lei a determinadas entidades que atendam aos requisitos nela fixados.

A partir da institucionalização da Lei 9.637/98, os estados da federação passaram a adotar o modelo de OS na gestão do SUS, destacadamente o Estado de São Paulo. Essa referência ao Estado paulista faz-se necessária por ser apresentado como modelo de sucesso na gestão da saúde para outros Estados da federação a partir dos anos 2000. 


\subsection{As Organizações Sociais: captura do fundo público pelo setor privado e a mercantilização da saúde}

Com a Lei das OSs, a Administração Gerencial consagrou a contrarreforma do Estado brasileiro e impulsionou a mercantilização dos setores rentáveis do serviço público de interesse coletivo, donde se encontram os serviços e unidades de saúde. Nesta lógica, a saúde pública - pelas necessidades de ajustes econômicos - se submete à lógica do mercado, que se põe materialmente e ideologicamente na vida social. Souza Filho (2011), na sua análise da administração gerencial no Brasil, conclui que "o projeto gerencialista ataca a finalidade de universalização de direitos [...]. Ratifica-se uma finalidade fundada no atendimento de necessidades mínimas da população, coerente com a proposição neoliberal de reforço do mercado.” (Souza Filho 2011, p. 96).

O modelo gerencial das Organizações Sociais segue a tendência crescente de repasse da gestão e do fundo público para o setor privado, denominado "público não-estatal", ou para instituições ditas estatais, mas com personalidade jurídica de direito privado. Como observa Correia (2017), "essas últimas permitem a regência dos interesses do mercado, dentro das instituições estatais e as liberta das amarras impostas pelas regras da administração pública do Estado" (Correia, 2017, p. 78). A autora afirma que esse processo

[...] significa transferência da gestão das atividades das políticas públicas para o setor privado mediante repasse de recursos, de instalações públicas e de pessoal. A isto se denomina privatização do público, ou seja, apropriação por um grupo privado (denominado 'não estatal') do que é público (Correia, 2011, p.45).

A captura do fundo público da saúde favorece o setor privado que passa a gerir as unidades de saúde, caracterizando a privatização não clássica, pois não acontece a venda direta de uma empresa pública, mas a terceirização da gestão de serviços públicos por meio de contratos de gestão com entidades de direito privado, mediante repasse de recursos, instalações, equipamentos públicos e pessoal. 


\section{As Organizações Sociais no município e no estado do Rio de Janeiro: a apropriação do fundo público, a crise financeira e o desmonte do sistema público de saúde}

A cidade do Rio de Janeiro foi pioneira na implementação das Organizações Sociais da Saúde (OSs) no estado, consolidando a terceirização dos serviços de saúde por meio da Lei Municipal no 5.026/09, sancionada em maio de 2009 pela prefeitura da cidade do Rio de Janeiro, mesmo diante da posição contrária do Conselho Municipal de Saúde (Lima e Bravo, 2015). Desse modo, para abordar a temática proposta neste item, inicialmente pontuaremos a condução das OSs no município do Rio de Janeiro em termos de recursos e de transferência da gestão e, posteriormente, atentaremos especificamente para as OSs contratualizadas pelo governo do Estado e os respectivos repasses financeiros via Contratos de Gestão, a fim de percebermos quanto em termos de recursos e de serviços de saúde estão nas mãos das OSs em todo estado fluminense.

\subsection{Organizações Sociais da Saúde no município do Rio de Janeiro: a apropriação do fundo público}

Como já afirmado, na cidade do Rio de Janeiro as OSs foram regulamentadas no ano de 2009 por meio da Lei 5.026/09 e do Decreto Municipal $\mathrm{n}^{\circ}$ 30.780 , de 2/06/2009. A referida Lei está em consonância com a Lei federal em muitos aspectos, como por exemplo, no que concernem as áreas de atuação ensino, pesquisa científica, desenvolvimento tecnológico, proteção e preservação do meio ambiente, cultura, saúde e esporte. Há duas peculiaridades importantes no primeiro artigo da referida Lei: a primeira, diz respeito a restrição a creches e reforço escolar para as OSs cujas atividades são dirigidas ao ensino. Já a segunda, diz respeito às OSs qualificadas para atuar na saúde. Essas só poderão atuar exclusivamente em unidades de saúde criadas a partir da entrada em vigor desta lei. Também estão previstas a atuação no Hospital Municipal Ronaldo Gazolla e nos equipamentos destinados ao Programa de Saúde da Família.

Como prevê a Lei federal 9.637/98, o processo de seleção das OSs se dá nos termos da lei de Licitações, na modalidade dispensa de licitação, mas com uma seleção conduzida pelo município. Assim, o processo de contratualização das OSs pela SMS/RJ se inicia com um edital de convocação pública de parcerias onde a secretaria municipal especifica sua intenção de desenvolver 
programas ou implantar unidades de saúde em áreas geográficas determinadas. Trata-se de um processo seletivo no qual as OSs qualificadas indicam propostas técnicas e econômicas a serem apresentadas publicamente a uma Comissão Especial de Seleção, a serem julgadas de acordo a certos critérios pré-definidos aprovados pela Secretaria. Tais recursos podem ser revistos anualmente pelo detalhamento dos objetivos do contrato e um valor máximo a ser destinado a ele (Lima e Bravo,2015) .

Desde 2009, quando a Lei 5026 foi sancionada, até o ano de 2019, vinte e duas entidades foram qualificadas como Organizações Sociais pela Comissão de qualificação da Secretaria Municipal de Saúde do Rio de Janeiro (COQUALI/SMS/RJ) para atuar no âmbito da saúde. As organizações sociais qualificadas serão apresentadas no quadro abaixo:

Quadro 1 - Organizações Sociais qualificadas para atuar na área da saúde no município do Rio de Janeiro.

\begin{tabular}{|l|l|}
\hline \multicolumn{1}{|c|}{ Organização Social } & Sigla \\
\hline Fundação para o desenvolvimento científica e tecnológico em saúde & FIOTEC \\
\hline Instituto de atenção básica e avançada à saúde & IABAS \\
\hline $\begin{array}{l}\text { Associação paulista para o desenvolvimento da medicina, programa } \\
\text { de atenção básica e saúde da família }\end{array}$ & SPDM \\
\hline Associação beneficente assistência social & PRÓ-SAÚDE \\
\hline Viva Rio & - \\
\hline Associação espaço produzir & - \\
\hline Instituto de psicologia clínica, educacional e profissional & IPCEP \\
\hline Instituto brasileiro de assistência e pesquisa & IBAP \\
\hline Centro de pesquisa em saúde coletiva & CEPESC \\
\hline Sociedade espanhola de beneficência - Hospital Espanhol & - \\
\hline $\begin{array}{l}\text { Instituto nacional de benefícios e assistência às cooperativas e associ- } \\
\text { ações - Instituto Advance }\end{array}$ & - \\
\hline Casa da árvore & - \\
\hline Centro de estudos e pesquisas 28 & CEP 28 \\
\hline Centro educacional nosso mundo & CENOM \\
\hline Sociedade beneficente caminho de damasco & SBCD \\
\hline Instituto de desenvolvimento institucional ação social & IDEIAS \\
\hline Hospital Maternidade Therezinha de Jesus & HMTJ \\
\hline Cruz Vermelha Brasileira & - \\
\hline Associação beneficiente israelita do Rio de Janeiro & - \\
\hline Instituto Lagos - RIO & - \\
\hline Instituto Gnosis & - \\
\hline Centro de estudos e pesquisas dr. João Amorim & CEJAM \\
\hline
\end{tabular}

Fonte: Secretaria Municipal de Saúde - RJ, 2018

Elaboração: Própria 
Desde a instituição da Lei até o ano de 2019, das entidades qualificadas acima, dez celebraram contratos com o município, de acordo com os Contratos de Gestão publicados no site da SMS. As contratadas pelo município foram: Associação Paulista para o Desenvolvimento da Medicina (SPDM); Fundação para o Desenvolvimento Científico e Tecnológico em Saúde (FIOTEC); Instituto de Ação Básica e Avançada a Saúde (IABAS); Viva Rio; Centro de Estudos e Pesquisas 28 (CEP-28); Centro de Estudos e Pesquisas "Dr. João Amorim" (CEJAM); Sociedade Espanhola de Beneficência; Instituto Gnosis; Hospital Maternidade Therezinha de Jesus e Cruz Vermelha. Outras Organizações Sociais, já desqualificadas ${ }^{5}$, também assumiram a gestão de unidades de saúde no período de 2009-2015. As Organizações Sociais desclassificadas foram: Associação Marca para Promoção de Serviços (A. Marca); Associação Social Global Soluções em Saúde - GLOBAL; BIOTECH - Humanas Organizações Sociais de Saúde; Centro Integrado e Apoio Profissional (CIAP); Fibra Instituto de Gestão e Saúde (FIBRA); Instituto SAS; Instituto Unir Saúde (SMS/RJ, 2016).

As Organizações Sociais da Saúde (OSS) no município do Rio de Janeiro se expandiram, principalmente, por meio da ampliação da cobertura do Programa Estratégia de Saúde da Família (ESF) que foi denominado de Clínica de Saúde da Família. Esse serviço de saúde foi implantado predominantemente por meio do contrato de gestão com as OS. Segundo o Plano Municipal de Saúde do Rio de Janeiro (2014), no período de 2008 a 2013, houve uma ampliação de 3,5\% para 41\% da cobertura de Saúde da Família. "Mais de 800 equipes foram implantadas e menos de 7\% delas estavam incompletas (CNES, 2013). Neste mesmo período, foram inauguradas 71 novas Clínicas da Família, ampliando a rede de saúde de 100 para 194 unidades" (PMS/RJ, 2014, p.49).

Desse modo, no primeiro ano em que vigorou a Lei municipal $\mathrm{n}^{\circ}$ 5.026/09, o objeto dos Contratos de Gestão celebrados com as OSs voltou-se predominantemente para as Clínicas de Saúde da Família e Unidades de Pronto Atendimento (UPAS). De 2009 em diante é possível observar a diversificação das unidades que passam a ser gerenciadas por OSs no município para além das Clínicas de Saúde da Família e UPAS, englobando também os Programas de Atendimento ao Idoso e nas Escolas, em 2010. De 2011 até o final de 2017 os Hospitais Gerais e de especialidades também passaram a ser gerenciados por

\footnotetext{
${ }^{5}$ As OS foram desqualificadas por diversas irregularidades amplamente denunciados pela mídia e pelo TCM/RJ. Tais irregularidades vão desde a constatação de sobrepreços na compra de insumos e medicamentos, a desvios milionários dos recursos financeiros repassados para gestação e manutenção das unidades de saúde que estavam responsáveis.
} 
OSs, demonstrando um crescimento considerável das OSs no município, e com ele uma transferência de recursos públicos da saúde cada vez maior. Os contratos de gestão formalizados desde 2009 até o final de $2017^{6}$ já somavam aproximadamente impressionantes R $\$ 11.974 .756 .303,47$ (SMS/RJ, 2020). Ressalta-se que no cálculo dos valores transferidos via Contrato de Gestão foram considerados, além do orçamento previsto para os doze primeiros meses de contrato, o acréscimo de recursos através dos termos aditivos, apostilamentos ${ }^{7}$ e a renovação do Contrato de Gestão ${ }^{8}$.

A gestão das OSs tem se mostrado problemática desde a sua institucionalização no município, amplamente denunciadas pelas auditorias do Tribunal de Contas do Município (TCM/RJ). O Relatório do TCM do município do Rio de Janeiro (2011) referente as UPAs municipais - UPAS da Cidade de Deus e da Vila Kennedy - aponta uma imensa contradição com o discurso de eficiência e economicidade das OSs em comparação com a gestão pública estatal. Ao comparar as despesas das referidas UPAS sob a gerência da OS IABAS, com os gastos e despesas de unidades diretamente gerenciadas pela Secretaria Municipal de Saúde e Defesa Civil (SMSDC) - os Centros Municipais de Saúde Jorge Saldanha Bandeira de Melo (Jacarepaguá) e Waldir Franco (Bangu) - o TCM/RJ identificou gastos excessivos. Dotada de autonomia para decidir sobre os procedimentos que devem adotar para a contratação de obras e serviços, bem como para compras e alienações

${ }^{6}$ Considerando que a maioria dos Contratos de Gestão tem vigência máxima de vinte e quatro meses, pode-se auferir que esse valor corresponde também aos repasses referentes a 2018 e 2019.Considerando o cenário da crise econômica, há possibilidades que o repasse tenha sido menor, uma vez que houve atrasos por parte da SMS/RJ no pagamento às OSs.

7 Apostilamento corresponde a um ato administrativo previsto no art. $65, \int 8^{\circ}$ da Lei 8 666/93. Em síntese, trata-se de um registro de variação contratual decorrente de reajuste de preços previsto no próprio contrato, atualizações, compensações ou penalizações financeiras em função das condições de pagamento nele previstas, bem como o empenho de dotações orçamentárias suplementares até o limite do seu valor corrigido (Cardoso, 2012).

${ }^{8}$ Os Contratos de Gestão têm, de forma geral, validade de vinte e quatro meses, sendo permitida a renovação, por meio de termos aditivos por igual período. Observamos que a renovação automática ocorre em praticamente todos os contratos do período citado. Nesse processo, é possível observar que a alocação dos recursos da saúde tem funcionado como uma fonte importante de sustentação dessas Organizações Sociais e seus grupos empresariais, aprofundando a tendência de focalização e precarização dos serviços de saúde. 
[...] a entidade contratada pela prefeitura pagou um preço por serviços, medicamentos e produtos com valores acima do que a própria prefeitura desembolsa com unidades de saúde diretamente sob sua gerência: [...] $56 \%$ a mais por serviços de limpeza, 168\% por remédios (antibióticos, antitérmicos, analgésicos e anti-inflamatórios) e $51 \%$ a mais por gases medicinais em relação às mesmas despesas nos centros de saúde (Cardoso, 2012, p.106).

Em auditoria realizada pelo TCM/RJ, em 2017, nos equipamentos de Estratégia de Saúde da Família - 229 unidades da Atenção Básica de Saúde, dis tribuídas entre as dez Áreas Programáticas (APs), com quatro Organizações Sociais (GNOSIS, IABAS, SPDM e VIVA RIO), no valor total de R $\$ 5,3$ bilhões, para um período de quatro anos - foram constatados indícios de que as metas físicas (quantidade de equipes de saúde da família) do cronograma de desembolso estavam superestimadas, pois a quantidade de pessoas cadastradas estava abaixo do que previsto no contrato.

De acordo com os auditores do TCM, o descumprimento das metas do cronograma de desembolso, e sua estimativa acima do necessário, refletem um custo adicional aos cofres do município de aproximadamente $\mathrm{R} \$ 59$ milhões/ ano. Evidencia também que o cadastramento de usuários estava abaixo do parâmetro utilizado para cálculo da quantidade de equipes e, consequentemente, para cálculo dos custos dos contratos de gestão. Importante destacar que esse desembolso acima do necessário para execução do contrato de gestão ocorre num contexto de dificuldades financeiras no fundo público municipal, levando ao não repasse de recursos, por parte da SMS/RJ, para diversos equipamentos de saúde.

A despeito do discurso dos defensores das Organizações Sociais, de que as mesmas são capazes de executar as funções do Estado no âmbito das políticas sociais de forma mais ágil, mais eficiente, efetiva e com menos custos, o Relatório do Tribunal de Contas do município do Rio de Janeiro (2011) referente as UPAs municipais - UPAS da Cidade de Deus e da Vila Kennedy aponta uma imensa contradição com esse discurso. Ao comparar as despesas das referidas UPAS sob a gerência da OS IABAS, com os gastos e despesas de unidades diretamente gerenciadas pela Secretaria Municipal de Saúde e Defesa Civil (SMSDC) - os Centros Municipais de Saúde Jorge Saldanha Bandeira de Melo (Jacarepaguá) e Waldir Franco (Bangu) - o TCM/RJ identificou gastos excessivos. Ressalta-se que as OSs têm autonomia para decidir sobre os procedimentos que devem adotar para a contratação de obras e serviços, bem como 
para compras e alienações.

Não há dados, nem mesmo produzidos pela SMS, atestando o bom desempenho das OSs no Rio de Janeiro, o que contraria um de seus anunciados pilares principais: accountability ${ }^{2}$. Avalia-se que é um modelo de gestão obscuro no que concerne a aplicação de recursos públicos da saúde incoerente com os princípios da administração pública. Os mecanismos de acompanhamento e fiscalização dos referidos contratos de gestão e das entidades de saúde que respondem a diversas irregularidades pelos Tribunais de Contas do país afora são frágeis, inclusive no estado do Rio de Janeiro.

\subsection{Crise da saúde no Rio de Janeiro e as Organizações Sociais: impactos no desmonte do sistema público de saúde}

O Estado do Rio de Janeiro, desde o ano de 2015, vem atravessando uma crise financeira sem precedentes. $\mathrm{O}$ governo atribui a crise à queda brusca na arrecadação, com a diminuição do Imposto sobre Circulação de Mercadorias e Serviços (ICMS), a diminuição dos royalties e a baixa nos preços dos barris de petróleo.

Uma característica que diferencia o Rio dos demais estados do país, é a alta dependência do petróleo, commodity ${ }^{10}$ que rendeu grandes lucros ao Estado fluminense nos últimos dez anos, quando o preço do barril de petróleo custava em média entre US\$110 e US\$150 (até 2014). Contudo, a crise econômica que se instalou no Brasil a partir do ano 2014 levou à queda na arrecadação do ICMS, e a do setor petroleiro, motivada pelos escândalos de corrupção na Petrobras investigados pela Operação Lava Jato ${ }^{11}$. No caso do ICMS, houve que-

9 Termo da língua inglesa que pode ser traduzido para o português como responsabilidade com ética e remete à obrigação, à transparência, de membros de um órgão administrativo ou representativo de prestar contas a instâncias controladoras ou a seus representados.

${ }^{10}$ Commodities são produtos "in natura", cultivados ou de extração mineral, que podem ser estocados por certo tempo sem perda sensível de suas qualidades. É uma forma de investimento, uma opção entre as tantas opções de investimento no mercado, como poupança ou Fundos de Investimento (Economia Br, 2016).

${ }^{11}$ Operação Lava Jato é um conjunto de investigações em andamento pela polícia federal do Brasil, cumprindo mais de mil mandados de busca e apreensão, de prisão temporária, de prisão preventiva e de condução coercitiva, visando apurar um esquema de lavagem de dinheiro que movimentou de 10 a 20 bilhões de reais em propina. Iniciada em 17 de março de 2014, a operação contava até fevereiro de 2016 com trinta e oito fases operacionais, durante as quais mais de cem pessoas haviam sido presas e condenadas (Wikipédia, 2016). 
da de 9,4\% na arrecadação do tributo entre 2014 e 2015. Já o barril de petróleo chegou a ser cotado a US\$ 30 em janeiro de 2016. Segundo dados da Agência Nacional do Petróleo, em 2014 o Estado do Rio de Janeiro recebeu 3,213 bilhões de reais. Em 2015, a quantia diminuiu para 2,308 bilhões e diminuiu ainda mais em 2016, chegando a 1,404 bilhão (Carta Capital, 2016).

De acordo com o economista Mauro Osório, coordenador do Observatório de Estudos sobre o Estado do Rio de Janeiro da Faculdade de Direito da UFRJ, em entrevista na Carta Capital (2016), para além da queda de arrecadação e no recebimento dos royalties ${ }^{12}$ pela exploração do petróleo, a crise financeira por qual passa o Estado é resultante também da concessão de incentivos fiscais para empresas privadas, sob o discurso da arrecadação e geração de empregos. Os dados do Tribunal de Contas do Estado (TCE) demonstram que, no período de 2008 a 2013, o Estado do Rio de Janeiro teria concedido o valor de $\mathrm{R} \$ 138$ bilhões de reais em renúncia fiscal. Osório também rejeita a tese em voga de que a crise do Estado seria resultante do aumento das despesas com a máquina estatal, com o aumento exagerado da folha de pagamento, uma vez que o estado deixou de realizar novos concursos por décadas. Segundo reportagem da Carta Capital (2016),

O Rio tem falta de funcionários, não excesso. O número de trabalhadores na ativa no serviço público estadual cresceu só 2,5\%, entre 2006 e 2014. No período de 2010 a 2014, houve queda de 3,7\%. Há escassez de concursos públicos desde o governo Chagas Freitas, na ditadura (Carta Capital, 2016).

Assim como em outros contextos de crise econômica, no pacote da crise atual ocorreu o corte/atraso no pagamento dos trabalhadores, prestadores de serviços, servidores do Estado do Rio de Janeiro e no repasse de recursos para manter os serviços públicos essenciais de interesse da coletividade, tais como a política de saúde.

Com a crise financeira do Estado veio à tona, de forma mais clara, o colapso dos serviços públicos de saúde, com seus principais sintomas expressos na deficiência, e até mesmo ausência de atendimento à população, inclusive nos serviços de urgências, falta de remédios, insumos básicos e equipamentos nos hospitais, além do atraso no pagamento dos médicos e demais funcionários etc. Em dezembro de 2015, a dívida com os fornecedores chegou a $\mathrm{R} \$ 1,4$ bilhões, e

\footnotetext{
${ }^{12}$ Os royalties de petróleo são os valores em dinheiro pagos pelas empresas produtoras aos governos para ter direito à exploração (O Globo, 2012).
} 
unidades de saúde chegaram a fechar parcialmente.

Observa-se que a crise do Estado alastrou a situação de calamidade pública para o âmbito das prefeituras, atingindo as unidades municipais de saúde de forma dramática. O Hospital Municipal Pedro II, sob gestão da OS SPDM, por exemplo, localizado no município do Rio de Janeiro, chegou a suspender internações e a reduzir as equipes de profissionais atuantes no hospital.

Entre 2017 e 2018, os gestores anunciaram déficit no orçamento municipal, passando, em 2018, a acontecer atrasos no pagamento de salários de profissionais de serviços gerenciados por algumas OSs em áreas da cidade, demissões de Agentes Comunitários de Saúde (ACS) e reduções do horário de funcionamento de unidades. Além dos esperados impactos no acesso, um dos efeitos prováveis deste processo foi a saída de profissionais, notadamente médicos, da APS municipal para outros municípios/estados e para o setor privado e a diminuição da chegada de novos profissionais.

A dívida do município do Rio de Janeiro bateu os $\mathrm{R} \$ 12$ bilhões ${ }^{13} \mathrm{em}$ 2017. Nesse período, hospitais municipais registraram superlotação, falta de insumos, equipamentos danificados. Com salários atrasados profissionais de saúde e funcionários chegaram a paralisar o atendimento à população carioca. A crise atingiu Clínicas de Saúde da Família, postos de saúde, e diversos hospitais municipais, dentre eles: Hospital Municipal Pedro II, Rocha Faria, Salgado Filho, Souza Aguiar. O quadro que ocorre no município se integra a situação de calamidade pública que já ocorria no setor estadual da saúde.

Em meados de 2018, a Secretaria Municipal de Saúde do Rio de Janeiro (SMS/RJ), sob a justificativa da crise financeira, apresentou o documento intitulado "Reorganização dos Serviços de Atenção Primária de Saúde - Estudo para Otimização de Recursos". Tal documento apontava, dentre outras medidas, para a necessidade de extinção de 184 Equipes de Saúde da Família, e 55 equipes de Saúde Bucal (cerca de 1400 postos de trabalho), e propunha nova tipologia de equipes, com base na Política Nacional de Atenção Básica modificada em 2017 (PNAB, 2017), que previu uma frágil composição profissional e alto número de usuários por equipe, apresentado como estratégia para qualificar e otimizar os serviços. De acordo com Melo et al. (2019),

A noção de produtividade foi central nesta proposta, compondo critérios para definir cortes de equipes e justificar sua permanência ou mudança, e adotando arranjos previstos na PNAB. O documento considerou haver ociosidade a priori nas equipes que cobriam abaixo de 3.000 habitantes,

${ }^{13}$ Revista EXAME, 2018. 
verificada pela produção de consultas, a despeito da ocorrência de greves, de possíveis efeitos do atraso de pagamentos no desempenho dos profissionais, do fato de boa parte das equipes atuarem em territórios afetados pela violência armada bem como da mudança do sistema de informação em curso na APS da cidade. Outro elemento que se destacou no estabelecimento dos critérios foi a redução de equipes em áreas consideradas privilegiadas (de classe média), a despeito da presença de comunidades pobres em tais bairros, da possível disputa simbólica ao atender pessoas de classe média, da diminuição de pessoas com planos privados de saúde e de outros impactos da crise na saúde das pessoas (Melo et al, 2019, p.4595-4596)

O estudo técnico do Tribunal de Contas do Município do Rio de Janeiro realizado em 2017, no bojo da Ação Civil Pública $n^{\circ}$ 0298494.15.2017.8.19.0001, atestou que o argumento da crise econômica e quedas das receitas não justificavam os cortes destinados à política de saúde carioca. Trata-se do contingenciamento de cerca de R $\$ 540$ milhões, ou seja, menos $10,77 \%$ do orçamento municipal da saúde, feito de forma desproporcional à redução das receitas (em 5,28\%), tendo por finalidade sua aplicação em outros setores não prioritários, tais como: Secretaria de Fazenda, Gabinete do Prefeito, Secretaria Municipal de Conservação e Meio Ambiente, num quadro extremamente grave da saúde municipal: faltavam insumos, medicamentos, recursos humanos, alimentação suficiente e adequada para profissionais de saúde e pacientes. Na rede hospitalar, o destaque era a superlotação, o pagamento dos profissionais de saúde em atraso e a suspensão de inúmeros contratos com serviços terceirizados, como de manutenção, maqueiros e segurança (Ação Civil Pública, 2019, p.03).

A interrupção progressiva dos serviços de saúde foi evitada pelo Ministério Público Estadual que deliberou pelo "descontingenciamento" dos recursos da saúde, indevidamente aplicado em outros setores. Contudo, a referida conjuntura voltou a se repetir em 2018, num cenário econômico de aumento de arrecadação de receitas, $\mathrm{R} \$ 67,5$ milhões a mais, segundo o jornal O Globo (2018). Tais constatações evidenciam o descompromisso do governo municipal com a saúde da população.

A Defensoria e o Ministério Público do Rio de Janeiro ao analisarem o estudo técnico realizado pelo TCM entenderam que, tanto em 2017 quanto em 2018, os decretos do Poder Executivo desviaram recursos de Programas de Saúde considerados estratégicos pelo próprio Município no Projeto de Lei Orçamentária. 
As ações civis públicas impetradas nos anos de 2017 e 2018 demonstraram que a crise econômica vivenciada afetou de forma desproporcional as atividades da prefeitura, sendo a SMS especialmente umas das mais prejudicadas, seja devido aos cortes na saúde, seja pelos atrasos nos pagamentos às Organizações Sociais, fornecedores e prestadores de serviços, o que ocasionou a paralisação de unidades de saúde. Nesse período, houve atrasos de salários dos funcionários das OS por mais de 1 mês, racionamento e restrição de insumos, ausência de manutenção predial, restrição de oferta de serviços de apoio diagnóstico e terapêutico, redução de ambulâncias do serviço de remoção de "Vaga Zero" e "Cegonha Carioca" (com tempo médio de espera para mais de 3 horas), dentre outros. Importante destacar que os hospitais da administração direta também reduziram procedimentos por ausência de insumos.

Num contexto de crise, a fragilidade dos vínculos trabalhistas imposto aos profissionais de saúde das OSs é demonstrada pela sua natureza jurídica, quando mais de 1500 trabalhadores foram demitidos sem substituição, já que não têm estabilidade. A gerência das unidades de saúde por diferentes Organizações Sociais, com características, estatutos e políticas de gestão do trabalho também distintas, impõem barreiras a organização política desses trabalhadores, cujos relatos de perseguições não são novos.

Os impactos para a saúde pública municipal vieram sob a forma de desassistência pela rede básica de mais de 1 milhão de pessoas. A ampliação da precarização do trabalho em saúde resultou também na vacância do profissional médico, e na sobrecarga dos que permaneceram, considerando o atendimento à população antes descrita pelas equipes extintas do ESF.

A despeito das promessas eleitorais, não houve aumento de oferta de procedimentos especializados e cirurgias. Em consulta à plataforma SISREG, no dia 05 de novembro de 2018 encontramos pendentes em fila, por exemplo: 14523 pessoas em espera para consulta por cirurgia de hérnia, 14458 para consulta por cirurgia de vesícula, 8914 para tratamento de catarata, $17271 \mathrm{em}$ consulta de urologia e subespecialidades, $5520 \mathrm{em}$ consulta para nefrologia. Mesmo procedimentos simples, como a triagem auditiva neonatal ("teste da orelhinha") que deveria ser executada ainda na maternidade (Ação Civil Pública, 2019, p.7).

Desse modo, o Rio de Janeiro vivenciou pelo terceiro ano consecutivo a agudização da crise na rede municipal e adentrou 2019 beirando ao colapso. Ainda em fevereiro de 2019, logo após a aprovação da lei orçamentária anual, a pasta da saúde sofreu um novo contingenciamento no valor total de $\mathrm{R} \$ 416 \mathrm{mi}$ - 
lhões. Já as Secretarias de Fazenda, a Procuradoria e a Controladoria do Município foram beneficiadas com aumento de suas dotações em um total de quase R\$ 15 milhões. Segundo a Defensoria e o Ministério Público do Rio de Janeiro (2019), trata-se de um total de $\mathrm{R} \$ 532$ milhões contingenciados, desses, $78 \%$ foram provenientes da Saúde, uma redução totalmente desproporcional em relação às demais pastas e que não encontra justificativa explicável para sua realização.

Contraditoriamente, as verbas com propaganda e publicidade do governo municipal não foram poupadas. Os valores destinados à publicidade e propaganda governamentais caminham para alcançar o maior patamar em três anos, como demonstra o quadro a seguir:

Quadro 2 - Gasto com publicidade e propaganda da Prefeitura do Rio de Janeiro - Total pago mais restos a pagar

\begin{tabular}{|l|c|c|c|c|c|}
\hline \multicolumn{1}{|c|}{ Órgão } & $\mathbf{2 0 1 5}$ & $\mathbf{2 0 1 6}$ & $\mathbf{2 0 1 7}$ & $\mathbf{2 0 1 8}$ & $\mathbf{2 0 1 9}$ \\
\hline $\begin{array}{l}1100 \text { - Casa Civil } \\
1116 \text { - Subsecretaria } \\
\text { de comunicação go- } \\
\text { vernamental }\end{array}$ & & & & & \\
\hline $\begin{array}{l}\text { Publicidade Propa- } \\
\text { ganda e Comunicação } \\
\text { Social }\end{array}$ & $\mathrm{R} \$ 105.419 .361,71$ & $\mathrm{R} \$ 95.588 .390,56^{*}$ & $\mathrm{R} \$ 8.804 .298,28$ & $\mathrm{R} \$ 35.124 .788,25$ & $\mathrm{R} \$ 62.956 .934,44^{* *}$ \\
\hline
\end{tabular}

*Até 2016 a publicidade estava alocada no órgão 1101- Gabinete da secretaria Municipal da Casa Civil

** Valor informado até 05/12/2019

Fonte: Portal Rio Transparente (2019)

Elaboração: Ministério Público do Rio de Janeiro (2019)

$\mathrm{Na}$ interpretação do Ministério Público, a prefeitura do Rio de Janeiro lançou mão dos recursos públicos para fins eleitoreiros, investindo na imagem e divulgação de ações governamentais cujo impacto seria benéfico num cenário eleitoral, como por exemplo a compra de novos equipamentos ("Renovação do Parque Tecnológico da Saúde") e reforma de instalações como a construção, ampliação e reforma em emergências. Tal condução, caracteriza ainda, desvio de finalidade disposto no art. $9^{\circ}$ da Lei de Responsabilidade Fiscal, já que, contingencia recursos destinados à Saúde de forma desproporcional às demais pastas, amparado em um suposto déficit de arrecadação de receitas, mantendo o maior corte na área da Saúde em relação a setores não prioritários. Acrescentese a isso, os bloqueios internos de despesas que configuram verdadeira não execução orçamentária na função saúde.

As vistorias realizadas em conjunto pelo Ministério Público e pela Defensoria Pública do Estado do Rio de Janeiro, nos dias 25 e 26 de novembro de 
2019, atestam o resultando caótico dessa política de desfinanciamento da saúde no Rio de Janeiro. Durante os dois dias da operação conjunta foram identificadas situações como insuficiência de leitos, superlotação das emergências, óbitos, desabastecimento expressivo de insumos e medicamentos e suspensão de cirurgias eletivas. Há um grave vazio assistencial ao qual está submetida a população carioca, com um quadro de desassistência da população.

A crise em curso na saúde pública do Rio de Janeiro é resultante da combinação de elementos locais e nacionais, expressos por escolhas políticas para operacionalização dos serviços de saúde, crise econômica do Estado e o avanço do gerencialismo no âmbito das políticas sociais.

Nessa direção, a sustentabilidade dos serviços de saúde pública do município do Rio de Janeiro sofre os limites impostos pelo modelo de gestão adotado, com vínculos trabalhistas frágeis, sucateamento de unidades, e o desmonte de equipes de saúde num contexto de falta de financiamento do SUS.

\section{Considerações finais}

As perspectivas gerenciais que avançaram sobre as políticas sociais em meados da década de 1990 têm impactado fortemente a consolidação do SUS público e estatal, uma vez que, o discurso de aperfeiçoamento da gestão do sistema e as terceirizações têm sido, na maioria das vezes, a regra, ignorando o desfinanciamento histórico dessa política pública tão importante.

Destaca-se que o quadro de desmonte da saúde municipal aqui apresentado foi permeado por enfrentamentos da sociedade civil organizada em defesa da saúde pública e contra a precarização do trabalho imposta pelas OSs. Nessa conjuntura, ganha corpo o movimento de resistência dos trabalhadores municipais, por meio de movimentos como "Nenhum serviço de saúde a menos", presença marcante dos profissionais da atenção primária municipal e da saúde mental, promovendo amplas mobilizações e denúncias junto a órgãos sindicais, legislativos e judiciários e greves, com interrupção parcial do funcionamento dos serviços.

A Frente Nacional contra a Privatização da Saúde (FNCPS) e o Fórum de Saúde do Rio de Janeiro vêm empreendendo também, ao longo dos anos, a luta contra todas as formas de privatização do SUS, especialmente, contra as Organizações Sociais. Faz-se a defesa da administração direta dos serviços públicos de saúde, por considerar que os modelos de gestão privatizantes capturam o fundo público da saúde, favorecem sua mercantilização e desmonta o 
SUS público estatal. Esse Fórum promoveu uma luta constante contra as OSs no Rio de Janeiro, desde a criação da Lei Estadual, por meio de mobilizações na Assembleia Legislativa, visita e entrega aos deputados estaduais de um documento solicitando o posicionamento contrário à sua criação, manifestações nas ruas, entre tantas outras lutas. A FNCPS empreendeu uma luta hercúlea em defesa da Ação Direta de Inconstitucionalidade (Adin) no 1923/98 sobre a Lei 12.637/98 que criou as OSs, em 2010, obtendo audiências com os Ministros do Supremo Tribunal Federal (STF) e entregando o documento "Contra fatos não há argumentos que sustentem as Organizações Sociais no Brasil”, inclusive junto ao então Ministro relator da referida Adin, Ayres Britto. Mobilizou entidades para entrarem com Amicus Curie em favor dessa Adin e participou das audiências sobre este tema no STF.

No contexto recente de ultraneoliberalismo, o processo de mercantilização da saúde tem se aprofundado, pois os empresários dessa área têm tido um maior protagonismo na definição da política de saúde ${ }^{14}$. Além de serem beneficiados com os recursos públicos, passam a ser formuladores da política de saúde brasileira e fortalecem a perspectiva do mix público e privado inscrito na proposta da Cobertura Universal da Saúde (CUS). Esta proposta subverte o caráter universal do SUS e propõe um neouniversalismo a partir de "[...] um mix entre provimento de saúde para população pobre pelo Estado e pelas Seguradoras de Saúde e planos privados para quem pude pagar" (Correia, 2018, p. 21).

No primeiro ano do governo Bolsonaro, o ataque ao SUS continua mais acelerado com questionamentos e ameaças a sua gratuidade e universalidade; anúncio da desvinculação de recursos para a saúde, entre outros. Em 2020, em plena pandemia do novo coronavírus, foi criada a Agência para o Desenvolvimento da Atenção Primária à Saúde (ADAPS) que aprofunda a precarização do trabalho em saúde e promove a terceirização da rede de atenção primária à saúde, com modelo de gestão semelhante às Organizações Sociais.

O contexto de enfrentamento da Covid-19 suscitará novos estudos so-

\footnotetext{
${ }^{14}$ A partir de 2016, no contexto dos governos ultraneoliberais - Temer e Bolsonaro -, o setor privado passa a ter uma proeminência na área da formulação da política de saúde brasileira. Nesse ano, houve uma maior aproximação do governo com o Instituto Coalisão Saúde (ICOS) para dialogar com os empresários da saúde (Bravo, Pelaez e Pinheiro, 2018). Em abril de 2018, foi realizado o evento "Agenda Saúde: a ousadia de propor um novo sistema de saúde", organizado pela recém-criada Federação Brasileira de Planos de Saúde (Febraplan), mais uma entre as várias entidades representativas de planos e seguros privados. No final desse mesmo mês, o presidente do ICOS, Claudio Lottenberg (dirigente da AMIL), defendeu a criação de um novo sistema de saúde para o país .
} 
bre o SUS e os limites de suas respostas às necessidades em saúde neste contexto, relacionando-os ao seu histórico de subfinanciamento e ao processo de privatização em curso há anos. Destaca-se que existem denúncias sendo apuradas no Rio de Janeiro sobre o envolvimento da OS IABAS com o desvio de recursos destinados a implantação e gestão de sete (7) hospitais de campanha para atender os doentes da Covid-19 desse estado. A mesma OS que o TCM/RJ identificou gastos excessivos em 2011 e em 2017, constatou indícios de que as metas físicas (quantidade de equipes de saúde da família) do cronograma de desembolso estavam superestimadas.

\section{Referências}

ANDREAZZI, Maria de Fátima Siliansky e BRAVO, Maria Inês Souza. Privatização da Gestão e Organizações Sociais na atenção à Saúde. In: Trabalho, Educação e Saúde. Rio de Janeiro, v.12 n.3, p 499-518, 2014.

BANCO MUNDIAL. Brasil: novo desafio à saúde do adulto. Washington D.C.: Banco Mundial,1991 (série de estudos do Banco Mundial sobre países).

A organização, prestação e financiamento da saúde no Brasil: uma agenda para os anos 90. Washington, D.C: Banco Mundial, 1995(Relatório n'12655- BR).

Diretrizes para aquisições no âmbito de empréstimos do BIRD e créditos da AID. Washington, D.C.: Banco Mundial, 1997.

Governança do Sistema Único de Saúde (SUS) brasileiro: Fortalecendo a Qualidade do Investimento Público e da Gestão de Recursos. Brasil, 15 de fevereiro de 2007 (Relatório no 36601 - BR).

20 anos de construção do sistema de saúde no Brasil: uma análise do Sistema Único de Saúde. Washington D.C., 2013.

Proposta de reforma do Sistema Único de Saúde brasileiro.

Washington D.C., 2019.

BRASIL. A Reforma administrativa do sistema de saúde. Caderno MARE, v. 13, 33p. Brasília: MARE, 1997

Lei n. ${ }^{\circ}$ 9.637, de 15 de maio de 1998. Dispõe sobre a qualificação de entidades como organizações sociais, a criação do Programa Nacional de Publicização, a extinção dos órgãos e entidades que menciona e a absorção de suas 
atividades por organizações sociais, e dá outras providências. Diário Oficial [da] República Federativa do Brasil, Brasília, 18 mai 1998. (Publicação Original).

Disponível em: < http://www.planalto.gov.br/ccivil 03/leis/19637.htm $>$ Acesso em julho de 2013.

BRAVO, Maria Inês Souza. Novas articulações entre o público e o privado no Sistema de Saúde Brasileiro: o caso do município do Rio de Janeiro. Projeto FAPERJ, 2012/2015. Rio de Janeiro: UERJ, 2015, mimeo.

; PELAEZ, Elaine Junger e PINHEIRO, Wladimir Nunes. As contrarreformas na política de saúde do governo Temer. Argumentum, v. 10, n. 1, p. 09-23, 2018.

CARDOSO, Aline Miranda. Organizações sociais na saúde: Rio Intransparente (Dissertação). Universidade do Estado do Rio de Janeiro, Rio de Janeiro, 2012.

CARTA CAPITAL. Entenda a crise e as razões da revolta de servidores no Rio de Janeiro. Net, jan. 2018. Disponível em: < https://www.cartacapital.com.br/politica/entenda-a-crise-e-a-revolta-dos-servidores-no-Rio-de-Janeiro/ >. Acesso em: 10 jan. 2018.

CORREIA, Maria Valéria Costa. Por que ser contra aos novos modelos de gestão do SUS?. In: BRAVO, Maria Inês Souza e MENEZES, Juliana Souza Bravo (org.) Saúde na atualidade: por um sistema único de saúde estatal, universal, gratuito e de qualidade. Rio de Janeiro: UERJ, Rede Sirius, ADUFRJ, 2011. p. 40-49.

Entre a Reforma Sanitária e o SUS: os interesses do capital na saúde. In: CORREIA, Maria Valéria Costa e SANTOS, Viviane Medeiros dos (org.) Reforma sanitária e Contrarreformas na saúde: interesses do capital em curso. Maceió: Edufal, 2017. p. 67-89.

O protagonismo do setor privado na saúde pública brasileira. In: CORREIA, Maria Valéria Costa (org.) Política de saúde no Brasil e o fortalecimento do setor privado: desmonte do SUS público, estatal e universal. Maceió: Edufal e Imprensa Oficial, 2018. p. 21-32.

DEFENSORIA PÚBLICA E MINISTÉRIO PÚBLICO DO RIO DE JANEIRO. Ação Civil Pública. Grupo de apoio técnico especializado, Ministério Público do Rio de Janeiro, Núcleo Saúde, 2019.

FRENTE NACIONAL CONTRA A PRIVATIZAÇÃO DA SAÚDE. Contra 
Fatos não há argumentos que justifiquem as Organizações Sociais. Net, mar. 2014. Disponível em: < https://www.contraprivatizacao.com.br/p/materiais.html>. Acesso em: março 2014.

LIMA, Joseane Barbosa e BRAVO, Maria Inês Souza. O percurso do financiamento das Organizações Sociais no município do Rio de Janeiro. In: BRAVO, Maria Inês Souza et al. (org). A mercantilização da saúde em debate: as Organizações Sociais no Rio de Janeiro. 1. ed. Rio Janeiro: UERJ, Rede Sirius, 2015.

LIMA, Joseane Barbosa. A privatização da saúde por meio das Organizações Sociais: a experiência do Rio de Janeiro. 2017. Tese (Doutorado). Universidade do Estado do Rio de Janeiro, Rio de Janeiro, 2017.

MELO, Eduardo Alves et al. A crise econômica e a atenção primária à saúde no SUS da cidade do Rio de Janeiro. Revista Brasileira Ciênc. saúde coletiva, v.24, n.12, p. 4.593-4.598. 2019.

O GLOBO. Prefeitura arrecadou R\$ $\mathbf{6 7 5}$ milhões após mudar IPTU. Net, fev. 2020. Disponível em: <https://oglobo.globo.com/rio/em-2018-prefeituraarrecadou-675-milhoes-mais-apos-mudar-iptu-22448365 >. Acesso em: 18 fev. 2020.

REVISTA EXAME. Prefeito do Rio culpa Olimpíada de 2016 por crise financeira. Net, fev. 2020. Disponível em: $<$ https://exame.com/brasil/prefeitodo-rio-culpa-olimpiada-de-2016-por-crise-financeira/>. Acesso em: 18 fev. 2020 .

REZENDE, Conceição Aparecida Pereira. O Modelo de Gestão do SUS e as Ameaças ao Projeto Neoliberal. Maria Inês Bravo et al. (org.). Cadernos de Saúde: política de saúde na atual conjuntura: modelos de gestão e agenda para a saúde. 2. ed. Rio de Janeiro, ADUFRJ, 2008. p. 25-35

RIO DE JANEIRO. Lei $\mathbf{n}^{\circ} \mathbf{5 0 2 6}$ de 19 de maio de 2009. Dispõe sobre a qualificação de entidades como Organizações Sociais e dá outras providências. Poder Executivo.

Conselho Municipal de Saúde do Rio de Janeiro. Plano Municipal de Saúde do Rio de Janeiro 2014-2017. Net, nov. 2016. Disponível em: $<\underline{\text { http: } / /}$ www.rio.ri.gov.br/dlstatic/10112/3700816/4128745/PMS 20142017.pdf>. Acesso em: 20 nov. 2016

Secretaria Municipal de Saúde do Rio de Janeiro. Relação das Organi- 
zações Sociais qualificadas no âmbito da Prefeitura da Cidade do Rio de Janeiro com as respectivas áreas de atuação, 2016.

Secretaria Municipal de Saúde do Rio de Janeiro. Relação das Organizações Sociais qualificadas no âmbito da Prefeitura da Cidade do Rio de Janeiro com as respectivas áreas de atuação, 2018.

Secretaria Municipal de Saúde do Rio de Janeiro. Reorganização dos

Serviços de Atenção Primária de Saúde - Estudo para Otimização de Recursos. Net, fev. 2020. Disponível em: < https://www.abrasco.org.br/site/wp-content/uploads/2018/11/REORGANIZA $\%$ C3\%87\%C3\%83O-DOS-SERVI $\%$ C3\%87OS-DE-ATEN $\%$ C3\%87\%C3\%83O-PRIM $\%$ C3\%81RIA-A-SA $\%$ C3\%9ADE-ESTUDO-PARA-OTIMIZA $\%$ C3\%87\%C3\%83O-DE-RECUR-

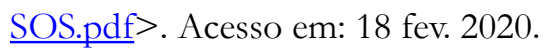

SOUZA FILHO, Rodrigo de. Gestão pública e democracia: a burocracia em questão. Rio de Janeiro: Lumen Juris, 2011.

TRIBUNAL DE CONTAS DO MUNICÍPIO DO RIO DE JANEIRO. Os avanços do controle externo na fiscalização das Organizações Sociais pelo Tribunal de Contas do Município do Rio de Janeiro. Net, fev. 2020. Disponível em: < http://www.tcm.ri.gov.br/Noticias/13138/tcerondonia.pdf>. Acesso em: 18 fev. 2020.> 